\title{
Low carbonyl reductase 1 expression is associated with poor prognosis in patients with oral squamous cell carcinoma
}

\author{
RYOTA YAMANOUCHI ${ }^{*}$, KOJI HARADA*, TARANNUM FERDOUS and YOSHIYA UEYAMA \\ Department of Oral and Maxillofacial Surgery, Yamaguchi University Graduate School of Medicine, \\ Ube, Yamaguchi 755-8505, Japan
}

Received February 6, 2017; Accepted October 20, 2017

DOI: $10.3892 / \operatorname{mco} .2018 .1548$

\begin{abstract}
Carbonyl reductase 1 (CBR1) is an enzyme that catalyzes the reduction of numerous compounds by using NADPH-dependent oxidoreductase activity. Decreased expression of CBR1 is associated with disease progression and an unfavorable outcome in several types of malignancies. The purpose of the current study was to determine whether CBR1 expression could be a useful prognostic factor in patients with oral squamous cell carcinoma (OSCC). Therefore, its mechanisms of action were investigated in order to understand how CBR1 affects cancer cell behavior in vitro. CBR1 expression was evaluated using immunohistochemistry and tissue samples obtained from 90 patients with OSCC. The associations between CBR1 expression, clinicopathological characteristics and patient survival were also analyzed. In addition, the role of CBR1 in cancer cell invasion and metastasis was examined, along with its underlying molecular mechanisms, via transfecting CBR1-siRNA into the HSC2 human OSCC cell line. Immunohistochemical analysis revealed that biopsy tissue samples of $71.1 \%$ of the patients with OSCC were positive for CBR1. In addition, CBR1 expression status was correlated with the $\mathrm{N}$ classification $(\mathrm{P}<0.0001)$, stage $(\mathrm{P}=0.0018)$ and outcome $(\mathrm{P}=0.0095)$. Furthermore, a statistical correlation was determined between the protein expression status and overall survival $(\mathrm{P}=0.0171)$. In vitro studies indicated that the suppression of CBR1 by CBR1-siRNA increased cancer cell proliferative, wound healing and migratory abilities. These findings suggest that low expression levels of CBR1 may affect cancer prognosis, and that CBR1 may have potential as a prognostic factor for patients with OSCC.
\end{abstract}

Correspondence to: Dr Koji Harada, Department of Oral and Maxillofacial Surgery, Yamaguchi University Graduate School of Medicine, 1-1-1 Minamikogushi, Ube, Yamaguchi 755-8505, Japan E-mail: harako@yamaguchi-u.ac.jp

*Contributed equally

Key words: oral squamous-cell carcinoma, carbonyl reductase 1, biomarker, poor prognosis

\section{Introduction}

Oral squamous-cell carcinoma (OSCC) is the most common type of cancer of the head and neck. There were 364,872 (147,897 females and 216,975 males) head and neck cancer-associated mortalities in Japan in 2013, according to the latest survey by the National Cancer Center (1). Also, $\sim 60 \%$ head and neck cancer cases diagnosed are patients in the advanced stages (stage III and stage IV) $(2,3)$. Despite modern advances in cancer therapy and clinical assessment, the survival rate has not improved substantially in recent years. Therefore, investigations must continue for the identification of suitable biomarkers to ensure early diagnosis or prognostic prediction for OSCC. The development of useful biomarkers may lead to the development of a novel therapeutic strategy or chemopreventive agents.

Carbonyl reductase (CBR) is an enzyme that catalyzes the reduction of numerous carbonyl compounds by using NADPH-dependent oxidoreductase activity $(4,5)$. There are two monomeric CBR genes ( $c b r l$ and $c b r 3)$ in the human genome. They exhibit high homology in their amino acid sequence (6). CBR1 has been studied regarding its ability to reduce a variety of carbonyl compounds, including antitumor anthracycline antibiotics, daunorubicin and doxorubicin, and prostaglandins $(6,7)$. Recently, it was reported that CBR1 serves an important role in regulating the malignant potential of cancer cells. In addition, the loss of CBR1 expression promotes tumor growth and metastasis $(8,9)$. Furthermore, reduced CBR1 expression is associated with lymph node metastasis and poor prognosis in ovarian cancer and uterine cervical cancer $(9,10)$. However, these reports did not indicate how decreased CBR1 levels may affect the malignant behavior of cancer. Furthermore, the role of CBR1 in OSCC has not yet been examined. Herein, the association between CBR1 expression patterns, lymph node metastasis and clinical prognosis in OSCC tissues was examined; the molecular mechanism by which CBR1 affects cancer cell invasion and metastasis in OSCC was also assessed.

\section{Materials and methods}

Clinical characteristics of patients and patient samples. Primary oral cancer tissue samples were obtained from 90 patients (46 males and 44 females; age range, 18-96 years) with OSCC who were treated at Yamaguchi University 
Hospital (Ube, Japan) from April 2006 to March 2012. All patients received curative surgery. Prior to primary treatment, tissue specimens were obtained from all 90 patients via biopsy. All tissue samples were fixed in phosphate-buffered $10 \%$ formalin and were paraffin-embedded (FFPE).

All tumors were staged according to the TNM classification of the UICC (2002) (11), and the degree of differentiation was determined according to the grade classification system of the World Health Organization (12).

Approval for this study protocol was obtained from the Institutional Review Board (IRB) and Ethical Committee of Yamaguchi University Hospital (Ref. H27-123). Informed consent was waived by the IRB as this was a retrospective study.

Immunohistochemical staining and the analysis of staining. Tissue biopsy samples obtained prior to surgery were used for immunohistochemical analyses. FFPE samples were heated in an autoclave at $121^{\circ} \mathrm{C}$ for $15 \mathrm{~min}$ in $10 \mu \mathrm{M}$ citrate buffer solution at $\mathrm{pH}$ 9.0. After quenching the endogenous peroxidase activity, the sections were treated for $2 \mathrm{~h}$ at room temperature with 10\% normal goat serum (cat. no. ab7481; Abcam, Cambridge, UK). The tissue sections were then incubated overnight at $4^{\circ} \mathrm{C}$ with rabbit-monoclonal anti-carbonyl reductase 1 (CBR1) antibody (dilution, 1:100; cat. no. ab156590; Abcam). After washing the tissue sections in PBS for 10 min at room temperature, the antibodies were detected using the Dako REAL ${ }^{\mathrm{TM}}$ EnVision $^{\mathrm{TM}}$ Detection system (cat. no. K5007; Agilent Technologies, Inc., Santa Clara, CA, USA), according to the manufacturer's protocol. Tissues were washed in PBS for $5 \mathrm{~min}$ at room temperature, and then counterstained with hematoxylin at room temperature for $1 \mathrm{~min}$. The tissue sections were subsequently dehydrated in $(70-100 \% \mathrm{v} / \mathrm{v})$ graded ethyl alcohol, dewaxed using xylene for $10 \mathrm{~min}$ at room temperature, and then mounted with glass coverslips using DPX mounting medium (Sigma-Aldrich; Merck KGaA, Darmstadt, Germany).

CBR1 expression was evaluated by the method described by Murakami et al (13) with minor modifications. Briefly, the intensity of CBR1 staining in cancer cells from cancerous tissues was compared with that in the normal adjacent oral epithelium. The immunoreactivity score was calculated as the sum of: (a) The percentage of positive cells $(0,0 \%$ immunopositive cells; $1,<50 \%$ positive cells; $2, \geq 50 \%$ positive cells); and (b) the staining intensity $(0$, negative; 1 , weak; 2 , moderate; 3 , high). The sum of the assigned values of the positive cells percentage (a) and the staining intensity (b) was $0-5$. Scores from 0-2 were regarded as low expression, whereas scores of 3-5 were regarded as high expression (Fig. 1). Immunoreactivity for CBR1 expression was evaluated by three authors, who were blinded to the patient's clinical status.

Cell lines and cell culture. OSCC cell lines (HSC2, HSC3, HSC4, SAS and Ca9-22) and $\mathrm{HaCaT}$ were obtained from the Cell Bank (RIKEN BioResource Center, Tsukuba, Japan). Cells were cultured in Dulbecco's modified Eagle's medium (DMEM; Sigma-Aldrich; Merck KGaA) supplemented with $10 \%$ fetal bovine serum (FBS; Thermo Fisher Scientific, Inc., Waltham, MA, USA), $100 \mu \mathrm{g} / \mathrm{ml}$ streptomycin and $100 \mathrm{U} / \mathrm{ml}$ penicillin (Thermo Fisher scientific) at $37^{\circ} \mathrm{C}$ in a humidified atmosphere containing $5 \% \mathrm{CO}_{2}$.
Small interfering (si)RNA transfection. The siRNA for CBR1 and non-targeting negative control siRNA were obtained from Thermo Fisher Scientific, Inc. The sequences of siRNA used for the study were as follows: CBR1 siRNA, sense, 5'-CAAGGU UGCUGAUCCCACATT-3' and antisense, 5'-UGUGGGAUC AGCAACCUUGAA-3'. Silencer Select Negative Control No.1 siRNA (Thermo Fisher Scientific, Inc.) was used as a nonspecific control. HSC2 cells were incubated with antibiotic-free DMEM supplemented with $10 \%$ FBS, then transfected with 75 pMCBR1 siRNA or negative control siRNA using a Lipofectamine ${ }^{\circledR} 3000$ Transfection kit (Thermo Fisher Scientific, Inc.) to generate CBR1 siRNA and negative control siRNA cell lines, respectively. Also, HSC2 cells were incubated with Lipofectamine ${ }^{\circledR}$ 3000 without any siRNA to generate a Lipofectamine cell line. The cells were transfected for $48 \mathrm{~h}$ prior to use for each experiment. As the HSC2 cell line has a better tumorigenic capacity than the other OSCC cell lines (14), only HSC2 was used for siRNA transfection with the aim of using the transfected cells for future in vivo mouse xenograft experiments.

Western blot analysis. HSC2, HSC3, HSC4, SAS, Ca9-22 and $\mathrm{HaCaT}$ cells were collected, centrifuged at $4^{\circ} \mathrm{C}$ and $390 \mathrm{x} \mathrm{g}$ for $5 \mathrm{~min}$, and lysed with radioimmunoprecipitation buffer (Wako Pure Chemical Industries, Ltd., Osaka, Japan). The quantity of protein from the whole cell lysates was quantified using a NanoDrop ${ }^{\mathrm{TM}} 1000$ spectrophotometer (Thermo Fisher Scientific, Inc.). A total of $20 \mu \mathrm{l}$ protein sample containing $50 \mu \mathrm{g} / \mathrm{ml}$ protein was loaded into each well of a NuPAGE ${ }^{\text {TM }}$ 4-12\% Bis-Tris gel (Thermo Fisher Scientific, Inc.) and separated using electrophoresis (200V, 110-125 mA gel, $40 \mathrm{~min})$, then transferred onto a polyvinylidene fluoride membrane using iBlot ${ }^{\circledR}$ gel transfer stacks (Thermo Fisher Scientific, Inc.). A blocking solution and a primary antibody dilution solution were made from WesternBreeze ${ }^{\circledR}$ Blocker/Diluent part A and B (cat. no. WB7050; Thermo Fisher Scientific, Inc.) according to the manufacturer's protocol. Following blocking at room temperature for $30 \mathrm{~min}$, the membranes were incubated with a rabbit-monoclonal anti-carbonyl reductase 1 (CBR1) antibody (dilution, 1:500; cat. no. ab156590; Abcam) or an anti- $\alpha$-tubulin mouse monoclonal antibody (dilution, 1:500; cat. no. sc-5286; Santa Cruz Biotechnology, Inc.) at $4^{\circ} \mathrm{C}$ overnight. Subsequently, the membranes were washed using 1X WesternBreeze ${ }^{\circledR}$ wash solution (Thermo Fisher Scientific, Inc.) three times at room temperature ( $5 \mathrm{~min} /$ wash), followed by incubation with Novex ${ }^{\circledR}$ alkaline-phosphatase conjugated goat anti-rabbit (cat. no. WP2007; Thermo Fisher Scientific, Inc.) or goat anti-mouse immunoglobulin G secondary antibodies (cat. no. WP20006; Thermo Fisher Scientific, Inc.) at room temperature for $30 \mathrm{~min}$. Following washing of the membranes three times with the wash solution at room temperature, protein bands were detected upon incubation of the membranes with Nove ${ }^{\circledR}$ AP Chromogenic substrate (cat. no. WP20001; Thermo Fisher Scientific, Inc.) at room temperature for 5-15 min. ImageJ v.1.51 h software (National Institutes of Health, Bethesda, MD, USA; http://imagej.nih.gov/ij/) was used to quantify the average intensities of each standard protein band, which were compared with the band intensities of the control protein, $\alpha$-tubulin.

In vitro cell viability assay. $\mathrm{HSC} 2$ cells $\left(4 \times 10^{3}\right.$ cells/well) were seeded onto 96-well plates (BD Biosciences, Franklin lakes, 
Table I. Patient characteristics.

\begin{tabular}{|c|c|c|}
\hline \multirow[b]{2}{*}{ Characteristics } & \multicolumn{2}{|c|}{ Total $(n=90)$} \\
\hline & No. patients & $\%$ of patients \\
\hline \multicolumn{3}{|l|}{ Sex } \\
\hline Male & 46 & 51.1 \\
\hline Female & 44 & 48.9 \\
\hline \multicolumn{3}{|l|}{ T classification } \\
\hline 1 & 20 & 22.2 \\
\hline 2 & 43 & 47.8 \\
\hline 3 & 5 & 5.6 \\
\hline 4 & 22 & 24.4 \\
\hline \multicolumn{3}{|l|}{$\mathrm{N}$ classification } \\
\hline 0 & 70 & 77.8 \\
\hline 1 & 11 & 12.2 \\
\hline 2 & 7 & 7.8 \\
\hline 3 & 2 & 2.2 \\
\hline \multicolumn{3}{|l|}{ Stage } \\
\hline I & 19 & 21.1 \\
\hline II & 38 & 42.2 \\
\hline III & 7 & 7.8 \\
\hline IV & 26 & 28.9 \\
\hline \multicolumn{3}{|l|}{ Outcome } \\
\hline Alive & 85 & 94.4 \\
\hline Mortality & 5 & 55.6 \\
\hline \multicolumn{3}{|c|}{$\begin{array}{l}\text { CBR } 1 \text { expression in } \\
\text { tumor cell cytoplasm }\end{array}$} \\
\hline Low & 26 & 28.9 \\
\hline \multirow[t]{2}{*}{ High } & 64 & 71.1 \\
\hline & Median & Min-max \\
\hline Age (years) & 68.0 & $18-96$ \\
\hline
\end{tabular}

CBR1, carbonyl reductase 1 .

NJ, USA) in DMEM supplemented with $10 \%$ FBS. After $48 \mathrm{~h}$, MTT was added to each well (25 $\mu \mathrm{l} /$ well) and incubated for $4 \mathrm{~h}$. After removing the MTT solution, $100 \mu \mathrm{l}$ dimethyl sulfoxide was added to each well and the absorbance was measured with a spectrophotometer (Bio Rad Laboratories, Inc., Hercules, CA, USA) at $490 \mathrm{~nm}$. All assays were run in triplicate.

Cell migration assay. A cell migration assay was performed using a Boyden chamber set (Neuro Probe, Inc., Gaithersburg, MD, USA), according to the manufacturer's instructions. A total of $5 \times 10^{3}$ HSC2 cells in $50 \mu$ l DMEM without FBS were seeded onto a gelatin-coated polycarbonate membrane. In the lower chambers, $25 \mu 1$ DMEM with $10 \%$ FBS was added as a chemoattractant. After the cells were incubated for $24 \mathrm{~h}$ at $37^{\circ} \mathrm{C}$ in a $5 \% \mathrm{CO}_{2}$ atmosphere, the polycarbonate membranes were washed with PBS and the cells on the top surface of the polycarbonate membrane were removed with a cotton swab. Cells adhering to the lower surface were fixed with $99.8 \%$ methanol at room temperature, counterstained with

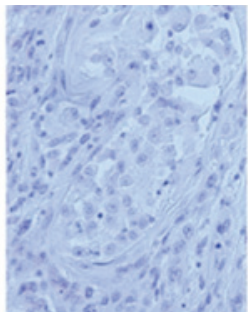

Negative control

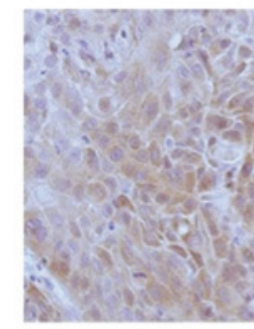

Moderate staining Strong staining

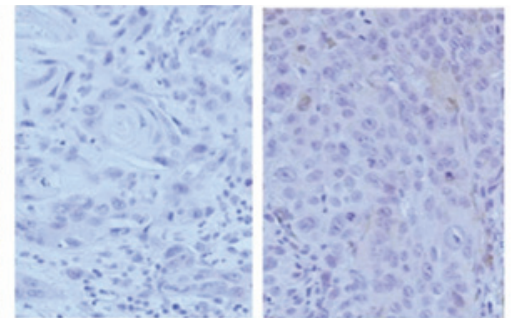

No staining Weak staining

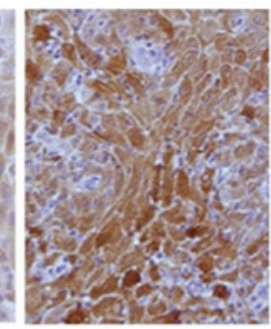

Figure 1. CBR1 expression in tissue samples stained with an anti-CBR1 antibody. CBR1 positive staining (brown cells) observed in the cytoplasm of tumor cells (x200). The immunoreactivity score was calculated as the sum of the percentage of positive cells $(0,0 \%$ immunopositive cells; $1,<50 \%$ positive cells; $2, \geq 50 \%$ positive cells); and the staining intensity ( 0 , negative; 1 , weak; 2 , moderate; 3 , high). The resultant value was $0-5$; values of $0-2$ were regarded as low expression and those of 3-5 were regarded as high expression. CBR1, carbonyl reductase 1.

hematoxylin solution at room temperature and counted under a light microscope in five predetermined fields (magnification, $\mathrm{x} 200$ ). All assays were independently repeated $\geq 3$ times.

Wound healing assay. HSC2 cells (1,510 3 cells per well) were seeded into a 24-well plate (BD Biosciences) and cultured in DMEM with $10 \%$ FBS and $1 \%$ penicillin/streptomycin until a monolayer formed. A $200-\mu 1$ pipette tip was used to gently wound the cell layer through the central axis of the plate. The migration of cells into the wounded area was examined after $24 \mathrm{~h}$ using a light microscope (BX-51-33-FLD2; Olympus Corporation, Tokyo, Japan). This assay was repeated three times.

Statistical analysis. For the analysis of CBR1 expression levels and associations between the clinicopathological variables in OSCC tissues obtained from patients, the chi-squared test was used. Overall survival (OS) of the patients with OSCC was defined as the time from treatment initiation to the date of mortality due to any cause. The Kaplan-Meier method was used to estimate the probability of OS in patients with OSCC as a function of time, and statistical differences in the survival time between patient subgroups were compared using the log-rank test. A multivariate survival analysis was performed using a Cox regression model to study the effects of CBR1 expression on OS of patients with OSCC. The Student's t-test was used to calculate the statistical significance among the various cells in the in vitro cell viability and migration assays. All P-values were based on two-tailed statistical analysis. $\mathrm{P}<0.05$ and $\mathrm{P}<0.01$ were considered to indicate statistically significant differences. All statistical analyses were conducted using StatView v.5.0J software (SAS Institute, Inc., Cary, NC, USA). 
Table II. Correlation of CBR1 expression and clinicopathological factors in OSCC.

\begin{tabular}{|c|c|c|c|c|}
\hline \multirow[b]{2}{*}{ Characteristic } & \multicolumn{2}{|c|}{ CBR1 expression in tumor cell } & \multirow[b]{2}{*}{ Total $(n=90)$} & \multirow[b]{2}{*}{${ }^{a}$ P-value } \\
\hline & Low expression $(\mathrm{n}=26,28.9 \%)$ & High expression $(n=64,71.1 \%)$ & & \\
\hline Sex & & & & 0.4897 \\
\hline Male & 15 & 31 & 46 & \\
\hline Female & 11 & 33 & 44 & \\
\hline Age & & & & 0.6409 \\
\hline$\geq 65$ & 17 & 38 & 55 & \\
\hline$<65$ & 9 & 26 & 35 & \\
\hline $\mathrm{T}$ classification & & & & 0.1302 \\
\hline $1+2$ & 15 & 48 & 63 & \\
\hline $3+4$ & 11 & 16 & 27 & \\
\hline $\mathrm{N}$ classification & & & & $<0.0001^{\mathrm{a}}$ \\
\hline 0 & 12 & 59 & 71 & \\
\hline $1+2+3$ & 14 & 5 & 19 & \\
\hline Stage & & & & $0.0018^{\mathrm{a}}$ \\
\hline $\mathrm{I}+\mathrm{II}$ & 10 & 47 & 57 & \\
\hline $\mathrm{III}+\mathrm{IV}$ & 16 & 17 & 33 & \\
\hline Outcome & & & & $0.0095^{\mathrm{a}}$ \\
\hline Alive & 22 & 63 & 85 & \\
\hline Mortality & 4 & 1 & 5 & \\
\hline
\end{tabular}

${ }^{\mathrm{a}} \mathrm{P}<0.05$ was defined as significant (Chi-squared test).

\section{Results}

Patients and tumor characteristics. The characteristics of the cohort of patients with OSCC are summarized in Table I. This study included a total of 90 patients with OSCC. The median follow-up time was 3.4 years, and the median patient age was 68 years (range, 18-96 years). For OSCC, clinical stages I, II, III and IV were identified in 19, 38, 7 and 26 patients, respectively, at the time of diagnosis.

CBRI expression in tumor cells and clinicopathological features. Table II details the correlations between CBR1 expression levels in tumor cells and certain clinicopathological features of patients. Among the 90 patients with OSCC, CBR1 expression in tumor cells was low in 26 patients (28.9\%) and high in 64 patients (71.1\%). CBR1 positivity in tumor cells was significantly associated with the $\mathrm{N}$ classification $(\mathrm{P}<0.0001)$, a higher clinical stage $(\mathrm{P}=0,0033)$ and a fatal outcome $(\mathrm{P}=0.0095)$. On the other hand, $\mathrm{CBR} 1$ positivity was not significantly correlated with sex, age and $\mathrm{T}$ classification at the time of diagnosis.

CBR1 expression in OSCCs and survival time. The overall median follow-up of the cohort was 3.4 years and mortality occurred in five cases. CBR1 positivity on tumor cell was associated with $\mathrm{OS}(\mathrm{P}=0.0171$; Fig. 2). Furthermore, multivariate analysis revealed that low expression levels of CBR1 $(\mathrm{P}=0.0485)$ and Stage III+IV $(\mathrm{P}=0.0466)$ are predictors of reduced survival, although no other variables were identified (Table III).

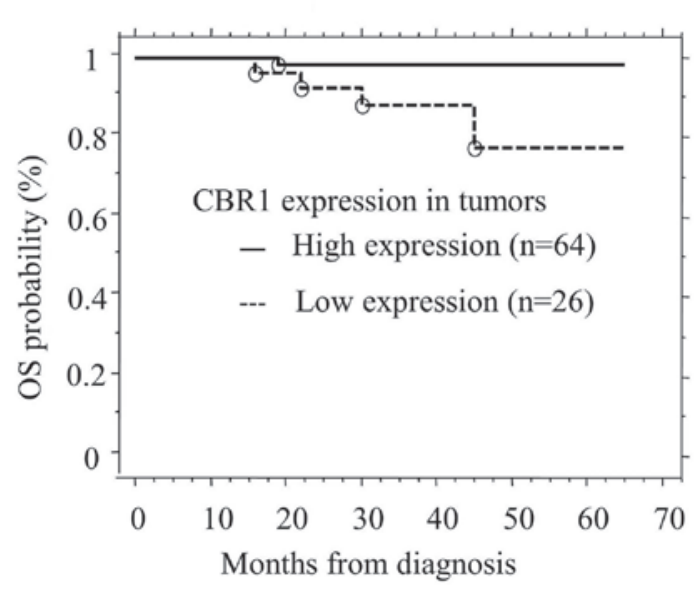

Figure 2. Correlation of CBR1 expression and overall survival (OS) in OSCC. The Kaplan-Meier method was used to estimate the probability of OS as a function of time. CBR1 positivity on tumor cell was associated with OS $(\mathrm{P}=0.0171)$. OS, overall survival; $\mathrm{n}$, number of patients; CBR1, carbonyl reductase 1; OSCC, oral squamous-cell carcinoma.

Analyses of protein expression of CBR1 in OSCC-derived cell lines. The level of CBR1 protein expression in OSCC-derived cell lines (HSC2, HSC3, HSC4, SAS and Ca9-22) and HaCaT was evaluated by western blot analysis. The highest expression of CBR1 was observed in HSC3 cells, the second highest expression was observed in HSC2 cells and the lowest was recorded in $\mathrm{HaCaT}$ cells, each when compared with all other cell lines (Fig. 3). 
Table III. Risk factors affecting overall survival rate determined by Cox's proportional hazards model.

\begin{tabular}{|c|c|c|c|}
\hline Variable & Hazard ratio & $95 \% \mathrm{CI}$ & ${ }^{\text {ap}} \mathrm{P}$-value \\
\hline T classification & & & 0.1537 \\
\hline $\mathrm{T} 3+\mathrm{T} 4$ vs. T1+T2 & 3.68 & $0.614-22.054$ & \\
\hline $\mathrm{N}$ classification & & & 0.2709 \\
\hline $\mathrm{N}+$ vs. N- & 2.753 & $0.456-16.399$ & \\
\hline Stage & & & 0.0466 \\
\hline Stage III+IV vs. Stage I +II & 6.178 & $1.028-37.131$ & \\
\hline CBR1 expression & & & 0.0485 \\
\hline High vs. low & 0.109 & $0.012-0.986$ & \\
\hline
\end{tabular}

CI, confidence interval; ${ }^{\mathrm{P}}<0.05$ was defined as significant.

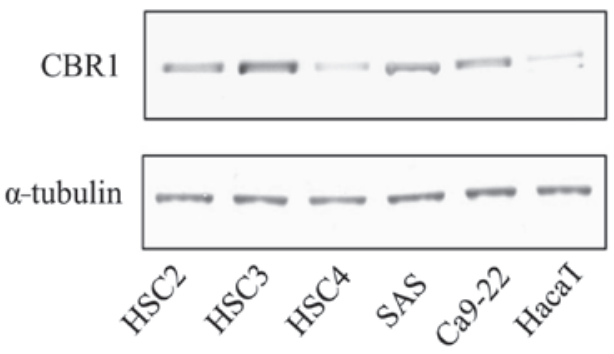

Figure 3. Expression of CBR1 protein in OSCC cells. Western blot analysis was performed to investigate protein levels of CBR1 in different OSCC cell lines. Expression of CBR1 in OSCC cells was variable. Highest expression of CBR1 was observed in HSC 3 cells and the lowest expression in HaCaT cells, while HSC2 exhibited the second highest expression compared to the other cell lines. $\alpha$-tubulin was used as an internal control. CBR1 protein band intensity for each cell type was quantified by comparing with that of $\alpha$-tubulin. CBR1, carbonyl reductase 1; OSCC, oral squamous-cell carcinoma.

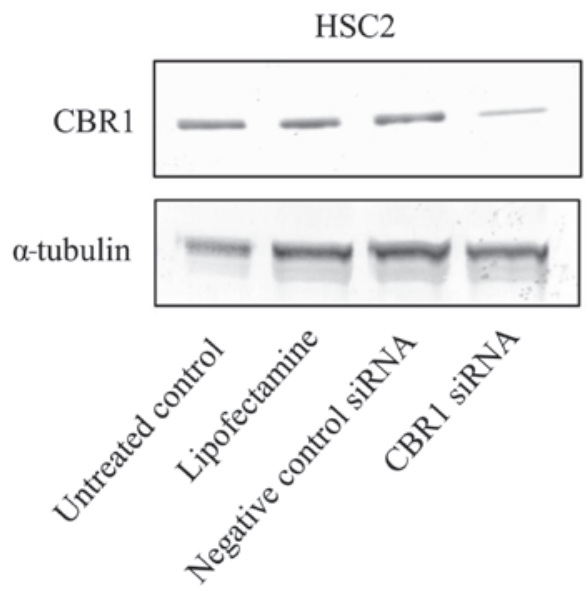

Figure 4. Downregulation of CBR1 by siRNA. HSC2 cells were transfected by CBR1 siRNA along with negative control siRNA. Western blot analysis revealed that transfection of CBR1 siRNA reduced CBR1 protein expression by 5.9 -fold in HSC2 cells compared with the untreated control. CBR1, carbonyl reductase 1; siRNA, small interfering RNA.

Downregulation of CBR1 by siRNA. To examine the role of CBR1 downregulation in the OSCC-derived cell line HSC2, downregulation experiments were carried out by transfecting HSC2 cells with CBR1 siRNA. HSC2 cells were used only

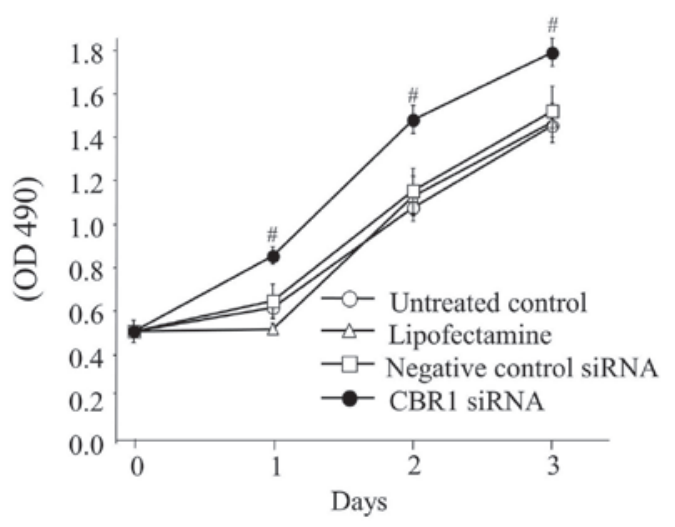

Figure 5. Cell viability assay. HSC2 cells $\left(4 \times 10^{3}\right.$ cells per well) were seeded on 96 -well plates, and cultured for $48 \mathrm{~h}$. Cell viability was evaluated by an MTT assay (OD490) in order to understand the proliferation rate of cells. The MTT assay revealed that the transfection of CBR1 siRNA promoted HSC2 cell growth. Error bars represent the standard deviation of the mean of three independent experiments. "P $\mathrm{P}<0.05$ when compared with that of the untreated control (Student's t-test). OD490, optical density or absorbance at $490 \mathrm{~nm}$; CBR1, carbonyl reductase 1; siRNA, small interfering RNA.

for siRNA transfection with the aim of using these transfected cells for future in vivo mouse xenograft experiments, as HSC2 cells have a better tumorigenic capacity than other OSCC cell lines according to our previous study (14). Western blot analysis confirmed a significant reduction (4 6.1-fold) in CBR1 protein expression in the transfected CBR1 siRNA cells, as compared with in the untreated control, Lipofectamine and negative control siRNA cells (Fig. 4).

Downregulation of CBRl enhances the cell growth ability. An MTT assay was performed with the untreated control HSC2 cells, Lipofectamine, CBR1 siRNA and negative control siRNA cells to check the viability of the cells, in order to evaluate the proliferation rate of the cells. The cells with low CBR 1 expression (CBR1 siRNA cells) exhibited significantly enhanced growth when compared with the other cells. These results suggest that CBR1 may be a critical factor affecting the growth of OSCC cells (Fig. 5).

Downregulation of CBRI enhances the cell wound healing and migration ability. Low expression of CBR1 is associated with 
$0 \mathrm{~h}$

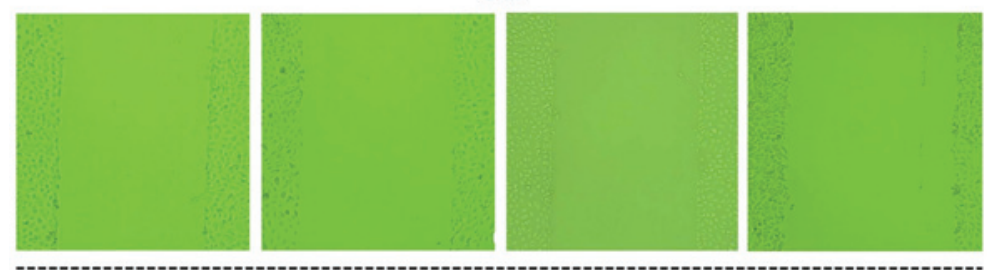

$24 \mathrm{~h}$

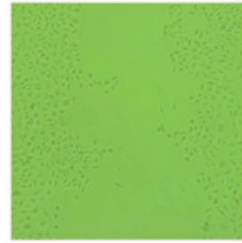

Untreated control

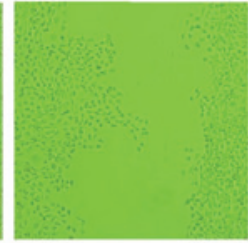

Lipofectamine

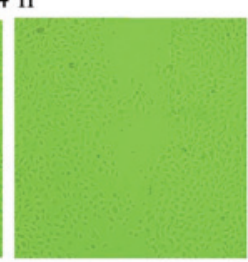

Negative control siRNA

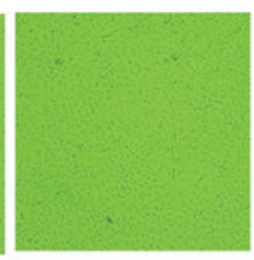

CBR1 siRNA

Figure 6. Wound-healing assay. The wound healing ability for the HSC2 cell transfectants was measured using a wound-healing assay. It was revealed that transfection of CBR1 siRNA promoted the wound healing ability of HSC2 cells. This assay was run in triplicate. CBR1, carbonyl reductase 1; siRNA, small interfering RNA.

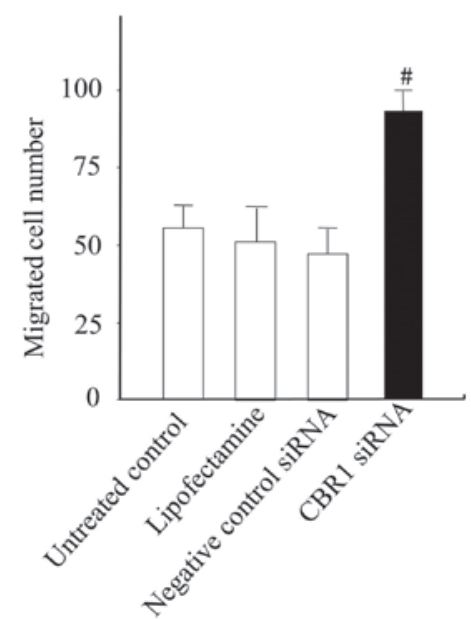

Figure 7. Migration assay. To evaluate the migration activity of the transfected HSC2 cells, a migration assay was performed using Boyden chambers. It was revealed that the transfection of $\mathrm{CBR} 1$ siRNA promoted the migration ability of HSC 2 cells. Error bars represent the standard deviation of the mean of three independent experiments. ${ }^{\#} \mathrm{P}<0.05$ when compared with that of thecontro (Student's t-test). CBR1, carbonyl reductase 1; siRNA, small interfering RNA.

cancer progression and metastasis. Therefore, a wound-healing assay was performed to examine the migration capabilities of the CBR1 siRNA and negative control siRNA cells. The migration activity of the transfected cells was also measured using a Boyden chamber assay. CBR1 siRNA cells exhibited higher wound healing and migration abilities compared with the untreated control, Lipofectamine and negative control siRNA cells (Figs. 6 and 7).

\section{Discussion}

In this study, it was demonstrated that decreased CBR1 expression is associated with a poor prognosis in OSCC, and therefore could be a useful prognostic factor for patients with OSCC. According to the findings, the usefulness of reduced CBR1 expression as a prognostic factor is almost equal to that of lymph node positive (N+) factor (Table III). Murakami et al (13) reported that reduced $\mathrm{CBR} 1$ expression could be a more useful predictive factor for poor prognosis than other pathological risk factors in patients with endometrial cancer. Murakami et al (13) also reported that decreased CBR1 expression was significantly associated with pelvic lymph node metastasis and a poor prognosis in uterine cervical cancer (9). In addition, Osawa et al (15) and Umemoto et al (10) reported that decreased CBR1 expression was correlated with growth, proliferation, lymph node metastasis and poor prognosis in ovarian cancer $(15,10)$. These studies suggest that using reduced CBR1 expression as a prognostic factor may be beneficial in gynecological cancer cases.

Similarly, it is possible that reduced CBR1 expression is important for OSCC as a prognostic factor as, histopathologically, the majority of gynecological cancer cases are squamous cell carcinoma (16). However, Miura et al (17) reported that CBR1 inhibits growth of ovarian cancer via tumor necrosis factor receptor signaling. Therefore, the role of CBR1 could vary between case studies of same type of cancer.

The present data also suggest that the downregulation of CBR1 expression serves an important role in the progression of OSCC cells, as the suppression of CBR1 expression increased cancer cell proliferation, wound healing and migration abilities (Figs. 5-7). Furthermore, it was observed that the expression of E-cadherin was decreased, and the secretion of matrix metalloproteinases (MMPs) was increased in cells with low CBR1 expression (data not presented). Reduced CBR1 expression may be associated with cervical lymph node metastasis and advanced stage of disease through the aforementioned mechanisms, as the loss of E-cadherin and the activation of MMPs induce cancer cell invasion and lymph node metastasis (18). Notably, Murakami et al (9) also reported that MMP activities are increased by CBR1 suppression through an increase of cytochrome $c$ oxidase subunit 2 (COX-2) in uterine squamous cell carcinoma cells. These reports support the findings that indicated the clinical significance of reduced CBR1 expression in OSCC.

It may be assumed that low expression or downregulation of CBR1 may correlate with malignant behavior in OSCC 
cells, consistent with the clinical data obtained (Fig. 2; Tables II and III). CBR1 expression is higher in cancer cells than in normal cells. However, CBR1 expression may be gradually reduced via the acquisition of malignant behaviors, including EMT, angiogenesis, and invasive and metastatic capacity $(8,13)$. EMT serves a significant role in tumor progression, invasion and metastasis, and E-cadherin loss is crucial to the EMT process (19). Decreased CBR1 expression is associated with lower E-cadherin expression and the promotion of EMT, which causes poor prognosis in endometrial cancer $(9,13)$. However, CBR1 expression levels in different OSCC cell lines frequently used for in vitro studies may not always correlate with the aggressiveness or invasive nature of the cells. In certain prior reports, HSC3 cells were characterized by poor differentiation and a high level of aggressiveness, whereas HSC2 cells were reported to have a high rate of differentiation and low invasive potential; HSC4 cells are reported to have a moderate differentiation rate with a low metastatic potential $(20,21)$. However, in the present study, high expression of CBR1 protein was observed in HSC 3 cells, while HSC2 cells exhibited moderate expression and HSC4 cells exhibited low CBR1 protein expression (Fig. 3). Therefore, further investigations with OSCC cells are required to verify whether low CBR1 expression promotes tumor progression and metastasis.

In future studies, to clarify the importance of CBR1 expression in OSCC, the authors intend to perform further siRNA studies using different OSCC cell lines, in addition to evaluating the growth, proliferation, migration and invasion capability of the transfected OSCC cell lines using more sensitive experiments, such as a bromodeoxyuridine assay, colony formation assay and a Boyden chamber assay. It is also necessary to carry out mouse xenograft experiments with these transfected cell lines in order to understand the effects of low CBR1 expression in vivo in the progression of tumors.

Based on the data, it is concluded that OSCC cells may frequently exhibit low levels of CBR1 expression, which may serve an important role in enhancing the metastatic potential of OSCC and disease progression. The data indicate that CBR1 expression may be useful for predicting the prognosis of OSCC. Immunohistochemical analyses of CBR1 expression may assist in determining whether adjuvant treatment is required or not. Furthermore, the present study provides a novel insight into the mechanisms involved in the malignant behavior of OSCC cells, and also suggests that CBR1 could be a novel target molecule to regulate cancer cell invasion and metastasis by molecular targeting therapy.

\section{Acknowledgements}

The present study was supported in part by a Grant-in-Aid Scientific Research (grant no. 15K11292) from the Ministry of Education, Culture, Sports, Science and Technology of Japan.

\section{Competing interests}

The authors declare that they have no competing interests.

\section{References}

1. http://ganjoho.jp/reg_stat/statistics/brochure/backnumber/2014_jp. html. Cancer statistics in Japan-2014. Accessed March 14, 2016.
2. National Comprehensive Cancer Network: NCCN clinical practice guidelines in oncology: Head and neck cancers. Version 1, 2012. http://www.ncen.org/clinical.asp. Accessed March 14, 2016.

3. Inagi K, Takahashi H, Okamoto MA, Nakayama M, Makoshi T and Nagai $\mathrm{H}$ : Treatment effects in patients with squamous cell carcinoma of the oral cavity. Acta Oto-Laryngol 122: 25-29, 2002.

4. Penning TM and Drury JE: Human aldo-keto reductases: Function, gene regulation, and single nucleotide polymorphisms. Arch Biochem Biophys 464: 241-250, 2007.

5. Mindnich RD and Pennning TM: Aldo-Keto Reductase (Akr) superfamily: Genomics and annotation. Hum Genomics 3: 362-370, 2009.

6. Miura T, Nishinaka T and Terada T: Different functions between human monomeric carbonyl reductase 3 and carbonyl reductase 1 . Mol Cell Biochem 315: 113-121, 2008.

7. Gonzales-Covarrubias V, Ghosh D, Lakhman SS, Pendyala L and Blanco JG: A functional genetic polymorphism on human carbonyl reductase 1 (CBR1 V88I) impacts on catalytic activity and NADPH binding affinity. Drug Metab Dispos 35: 973-980, 2007.

8. Ismail E, Al-Mulla F, Tsuchida S, Suto K, Motley P, Harrison PR and Birnie GD: Carbonyl reductase: A novel metastasis-modulating function. Cancer Res 60: 1173-1176, 2000.

9. Murakami A, Fukushima C, Yoshidomi K, Sueoka K, Nawata S, Yokoyama Y, Tsuchida S, Ismail E, Al-Mulla F and Sugino N: Suppression of carbonyl reductase expression enhances malignant behaviour in uterine cervical squamous cell carcinoma: Carbonyl reductase predicts prognosis and lymph node metastasis. Cancer Lett 311: 77-84, 2011.

10. Umemoto M, Yokoyama Y, Sato S, Tsuchida S, Al-Mulla F and Saito Y: Carbonyl reductase as a significant predictor of survival and lymph node metastasis in epithelial ovarian cancer. Brit J Cancer 85: 1032-1036, 2001.

11. Leslie SH and Christian W (eds): TNM Classification of Malignant Tumours. 6th edition. International union against cancer (UICC). Wiley-Blackwell, pp264, 2002.

12. Pindborg JJ, Reichart PA, Smith CJ and van der Waal I: Histological typing of cancer and precancer of the oral mucosa, 2nd edition. World health organization (WHO). Springer-verlag, pp87, 1997.

13. Murakami A, Yakabe K, Yoshidomi K, Sueoka K, Nawata S, Yokoyama Y, Tsuchida S, Al-Mulla F and Sugino N: Decreased carbonyl reductase 1 expression promotes malignant behaviours by induction of epithelial mesenchymal transition and its clinical significance. Cancer Lett 323: 69-76, 2012.

14. Harada K, Ferdous T and Ueyama Y: Establishment of 5-fluorouracil-resistant oral squamous cell carcinoma cell lines with epithelial to mesenchymal transition changes. Int J Oncol 44: 1302-1308, 2014.

15. Osawa Y, Yokoyama Y, Shigeto T, Futagami M and Mizunuma $\mathrm{H}$ : Decreased expression of carbonyl reductase 1 promotes ovarian cancer growth and proliferation. Int J Oncol 46: 1252-1258, 2015.

16. Cervical Cancer Treatment $\left(\mathrm{PDQ}^{\circledR}\right)$-Health Professional Version. National Cancer Institute.Website: https://www.cancer. gov/types/cervical/hp/cervical-treatment-pdq\#section/. Accessed August 31, 2016.

17. Miura R, Yokoyama Y, Shigeto T, Futagami M and Mizunuma H: Inhibitory effect of carbonyl reductase 1 on ovarian cancer growth via tumor necrosis factor receptor signaling. Int $\mathrm{J}$ Oncol 47: 2173-2180, 2015.

18. Schipper JH, Frixen UH, Behrens J, Unger A, Jahnke K and Birchmeier W: E-cadherin expression in squamous cell carcinomas of head and neck: Inverse correlation with tumor dedifferentiation and lymph node metastasis. Cancer Res 51: 6328-6337, 1991.

19. Thiery JP and Sleeman JP: Complex networks orchestrate epithelial mesenchymal transitions. Nat Rev Mol Cell Biol 7: 131-142, 2006.

20. Momose F, Araida T, Negishi A, Ichijo H, Shioda S and Sasaki S: Variant sublines with different metastatic potentials selected in nude mice from human oral squamous cell carcinomas. J Oral Pathol Med 18: 391-395, 1989.

21. Takahashi H, Shigeta T, Umeda M and Komori T: A new in vitro invasion model for oral cancer using an acellular allogenic dermal matrix (Alloderm): The relationship among in vitro invasion activity, in vivo invasion and metastasis. Kobe J Med Sci 57: E128-E136, 2012. 